\title{
Experimental Research on Toluene Degradation in Plasma as the Driving Force of Nanomaterials
}

\author{
Tao Zhu*, Xiaoyang Li, Wenjuan Zhao, Ni Xia, Xiaojia Wang \\ School of Chemical \& Environmental Engineering, China University of Mining \& Technology, Beijing, China \\ Email: ${ }^{\text {bamboozt@ @umtb.edu.cn }}$
}

Received 16 Septemper 2015; accepted 20 October 2015; published 23 October 2015

Copyright (C) 2015 by authors and Scientific Research Publishing Inc.

This work is licensed under the Creative Commons Attribution International License (CC BY). http://creativecommons.org/licenses/by/4.0/

cc) (i) Open Access

\begin{abstract}
Plasma technology has some shortcomings, such as higher energy consumption and byproducts produced in the reaction process. However non-thermal plasma associated with catalyst can resolve these problems. So this kind of technology was paid more and more attention to treat waste gas. In this paper, we make use of this technology to decompose toluene under different electric field and packed materials. At the same time, the mechanism of toluene decomposition using plasma and catalyst is discussed. The experimental results show toluene decomposition increases with electric field strength increasing and flow velocity and initial concentration decreasing. There are four conditions in plasma: without packed materials (1); with packed materials (2); with $\mathrm{BaTiO}_{3}$ in the surfaces of packed materials (3); and with nanometer $\mathrm{Ba}_{0.8} \mathrm{Sr}_{0.2} \mathrm{Zr}_{0.1} \mathrm{Ti}_{0.9} \mathrm{O}_{3}(4)$. Toluene decomposition represents a obvious trend, that is, $\eta(4)>\eta(3)>\eta(2)>\eta(1)$. The best decomposition efficiency of toluene arrives at $95 \%$.
\end{abstract}

\section{Keywords}

Non-Thermal Plasma, Toluene, Decomposition Efficiency, Nano-Materials

\section{Introduction}

Volatile organic compounds (VOCs) are triggering serious environmental problems such as stratospheric ozone depletion and photochemical smog. Although toluene is an important chemical feedstock and additive, it should be removed from exhaust gases emitted from various moving and stationary sources due to its carcinogenicities and respiratory disorders [1].

\footnotetext{
${ }^{*}$ Corresponding author.
} 
The traditional methods of VOCs removal such as absorption, adsorption, and incineration and so on, which were referred to the new environmental condition, had many technical and economic disadvantages [2].

In these years, some new technologies, such as biologic process, photocatalysis process, and plasma technology, were paid more and more attention [3]-[5]. In particular, non-thermal plasma has attracted much attention as a method for VOCs control for two decades due to its unique properties such as quick response at ambient temperature, achievement of high electron energies within short residence times, system compactness, and easy operations. In order to improve the energy efficiency of the VOCs decomposition process by the plasma, the cooperation with catalyst has been tested by some researchers [6]-[8]. Ruixing Li et al. [9] reported that the ratio of $\mathrm{CO}_{2}$ decomposition using $\mathrm{Ca}_{0.7} \mathrm{Sr}_{0.3} \mathrm{TiO}_{3}$ was much greater than commercial alumina and silica glass barriers, so as to obtain a conclusion that the $\mathrm{CO}_{2}$ conversion was proportional to the permittivity of the dielectric barrier materials. Muhammad Arif Malik et al. [10] indicated that $\mathrm{C}_{2} \mathrm{HCl}_{3}$ destruction was significantly improved by packing the discharge gap with alumina pellets, compared with in the case of no padding. These studies show that the combination of discharge plasma with nano-materials is a very effective method in VOCs removal.

In this paper, we tried the combination of non-thermal plasma with nanometer $\mathrm{Ba}_{0.8} \mathrm{Sr}_{0.2} \mathrm{Zr}_{0.1} \mathrm{Ti}_{0.9} \mathrm{O}_{3}$ as catalyst for toluene removal, in order to further reduce the energy consumption and harmful byproducts in plasma process.

This paper illuminates the experimental results of the synergistic effect of non-thermal plasma generated by dielectric barrier discharge (DBD) and nano-materials on toluene decomposition.

\section{Experimental Part}

\subsection{Reaction System}

NTP coupled with catalyst was used for toluene removal from a gaseous influent at normal temperature and atmospheric pressure. The NTP system consists of a tube-wire packed-bed reactor system, an AC power supply (frequency of $150 \mathrm{~Hz}$ ), a continuous flow gas supplying system and an electric and gaseous analytical system. The schematic diagram of NTP system is shown in Figure 1. Dry air $\left(78 \% \mathrm{~N}_{2}, 21 \% \mathrm{O}_{2}\right)$ was used as a balance gas for toluene decomposition. Air supplied from an air compressor was divided into two air flows with each flow rate controlled by a mass flow controller (MFC). One dry air flow was introduced into a bottle of liquid toluene to produce saturated toluene. The vapor was then mixed with the other dry air flow in a blender so that toluene waste gas was diluted to a desired concentration.

The NTP packed-bed reactor is shown in Figure 2. The coaxial cylindrical NTP reactor consists of an organic glass tube with an inner diameter of $32 \mathrm{~mm}$ and wall thickness of $3 \mathrm{~mm}$ wrapped by a steel mesh of $20 \mathrm{~cm}$ in length as a ground electrode. A tungsten wire $(0.5 \mathrm{~mm}$ in diameter) placed on the axis of NTP reactor served as the inner discharge electrode. The relative humidity of $25 \%$ in NTP reactor was controlled by a thermohygrometer, and the temperature is $20^{\circ} \mathrm{C}$.

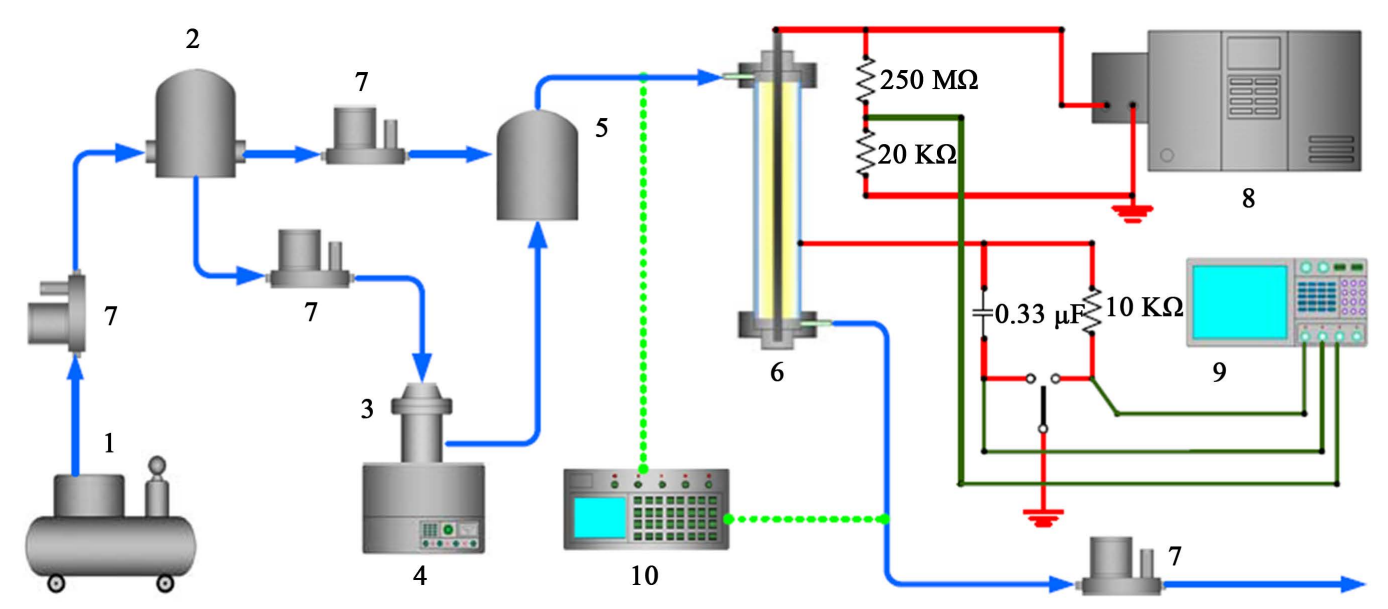

Figure 1. Schematic diagram of NTP system for toluene removal. 1. Air compressor; 2. Buffer; 3. Toluene liquid bottle; 4. Attemperator; 5. Blender; 6. NTP reactor; 7. Mass flow meter; 8. High voltage; 9. Oscillograph; 10. Gas chromatograph. 




Figure 2. NTP reactor. Reactor: organic-glass tube (i.d. $32 \mathrm{~mm}$, packed infilling length of packed materials of $200 \mathrm{~mm}$ ); Internal electrode: tungsten filament (i.d. $0.5 \mathrm{~mm}$ ); External electrode: dense steel mesh.

\subsection{Materials and Methods}

In the experiment, three kinds of packing materials, including ceramic rings, $\mathrm{BaTiO}_{3}$ rings and $\mathrm{Ba}_{0.8} \mathrm{Sr}_{0.2} \mathrm{Zr}_{0.1} \mathrm{Ti}_{0.9} \mathrm{O}_{3}$ rings (hollow cylinder shape, $5 \mathrm{~mm}$ i.d., $1 \mathrm{~mm}$ wall thick, and $10 \mathrm{~mm}$ length), were used to pack into the NTP reactor.

Nano-size $\mathrm{Ba}_{0.8} \mathrm{Sr}_{0.2} \mathrm{Zr}_{0.1} \mathrm{Ti}_{0.9} \mathrm{O}_{3}$ powder was prepared using the method of water-thermal composite action at atmospheric pressure. Inorganic salts, including $\mathrm{TiCl}_{4}, \mathrm{Ba}(\mathrm{OH})_{2} \cdot 8 \mathrm{H}_{2} \mathrm{O}$ and $\mathrm{Sr}(\mathrm{OH})_{2} \cdot 8 \mathrm{H}_{2} \mathrm{O}$, were the precursors for $\mathrm{Ba}_{0.8} \mathrm{Sr}_{0.2} \mathrm{Zr}_{0.1} \mathrm{Ti}_{0.9} \mathrm{O}_{3}$ formation. Firstly, a proper quantity of $\mathrm{TiCl}_{4}$ was added to $100 \mathrm{~mL}$ water as the precursor solution and ammonia used to adjust $\mathrm{pH}$ to 7 . By strictly controlling the reaction conditions in a ventilation cabinet, the precursor solution hydrolyzed to $\alpha-\mathrm{H}_{2} \mathrm{TiO}_{3}$. And then, $\mathrm{Cl}^{-}$was removed by hot water washing and filtrated by decompression and boiled at $100^{\circ} \mathrm{C}$ for 4 hours. Certain amounts of $\mathrm{Ba}(\mathrm{OH})_{2} \cdot 8 \mathrm{H}_{2} \mathrm{O}$ and $\mathrm{Sr}(\mathrm{OH})_{2} \cdot 8 \mathrm{H}_{2} \mathrm{O}$ dropped into $\mathrm{H}_{2} \mathrm{TiO}_{3}$ and ammonia adjusted $\mathrm{pH}$ to 6 - 6.5 and the solution was shielded from air and agitated for hours. During the preparation, if needed, water was added to keep the balance of the liquid quantity. Where after, gained solid (nano- $\mathrm{Ba}_{0.8} \mathrm{Sr}_{0.2} \mathrm{Zr}_{0.1} \mathrm{Ti}_{0.9} \mathrm{O}_{3}$ ) was ground to powders and dried at $100^{\circ} \mathrm{C}$ in a crucible. The powder was made into rings ( $5 \mathrm{~mm}$ i.d., $1 \mathrm{~mm}$ wall thick, and $10 \mathrm{~mm}$ length) which were placed in a muffle furnace to calcine at $1200^{\circ} \mathrm{C}$ for two hours. The calcined product was cooled to ambient temperature and served as the packing materials in the NTP reactor. At the same time, a $\mathrm{BaTiO}_{3}$ (powders made in Beijing Research Institute of Chemical Engineering \& Metallurgy) ring was also made with the same weight as the $\mathrm{Ba}_{0.8} \mathrm{Sr}_{0.2} \mathrm{Zr}_{0.1} \mathrm{Ti}_{0.9} \mathrm{O}_{3}$ ring.

The crystal structure and the surface shape of the $\mathrm{Ba}_{0.8} \mathrm{Sr}_{0.2} \mathrm{Zr}_{0.1} \mathrm{Ti}_{0.9} \mathrm{O}_{3}$ sample were detected by XRD (manufactured by Germany Bruker Co., D8 ADVANCE) and SEM (manufactured by Japan, JEOL-JSM-6500F) and the BET surface area determined by Micrometrics (manufactured by American Quanta chrome Co., NOVA 1000). The relative permittivity of the $\mathrm{Ba}_{0.8} \mathrm{Sr}_{0.2} \mathrm{Zr}_{0.1} \mathrm{Ti}_{0.9} \mathrm{O}_{3}$ sample was measured using an LCR automatism test instrument (manufactured by China, 4210). Toluene analysis was carried out by gas chromatography (manufactured by Aglient Co., HP6890N) with a flame ionization detector (FID). The byproducts were detected by GC-MS (manufactured by American Thermo Finnegan Co.) using EI mode, $70 \mathrm{eV}$ and full scan. Ozone concentration produced in the NTP reactor was measured by an iodine-titration method. The plasma reactor employed an AC power supply of $150 \mathrm{~Hz}$ scanning from $0 \mathrm{kV}$ to $100 \mathrm{kV}$ was applied to the reactor in the radial direction. The voltage and current waveforms were measured by oscillograph (manufactured by American Tektronix Co., TDS2014). To investigate the electric characteristics of dielectric barrier discharge (DBD), the voltage applied to the reactor was sampled by a voltage divider with a ratio of 12,500:1. Also, the current was determined from the voltage drop across a shunt resistor $(\mathrm{R} 3=10 \mathrm{k} \Omega$ ) connected in series with the grounded electrode. In order to obtained the total charge and discharge power simultaneously, a capacitor $(\mathrm{Cm}=2 \mu \mathrm{F})$ was inserted between the reactor and the ground. The electrical power provided to the discharge was measured using the Q-V Lissajous diagram. Typical Lissajous diagram represents to be a parallelogram, and we could calculate power though calculated the area of parallelogram.

As evaluation criterion, the decomposition efficiency of toluene was calculated as follows:

$$
\eta=\frac{C_{0}-C}{C_{0}} \times 100 \%
$$

where $C_{0}$ and $C$ indicate inlet and outlet concentrations of toluene, respectively. 


\section{Decomposition Mechanism}

According to one of reaction mechanisms, high energy electrons react with toluene molecules as follows in the reaction process of the NTP technology [11]:
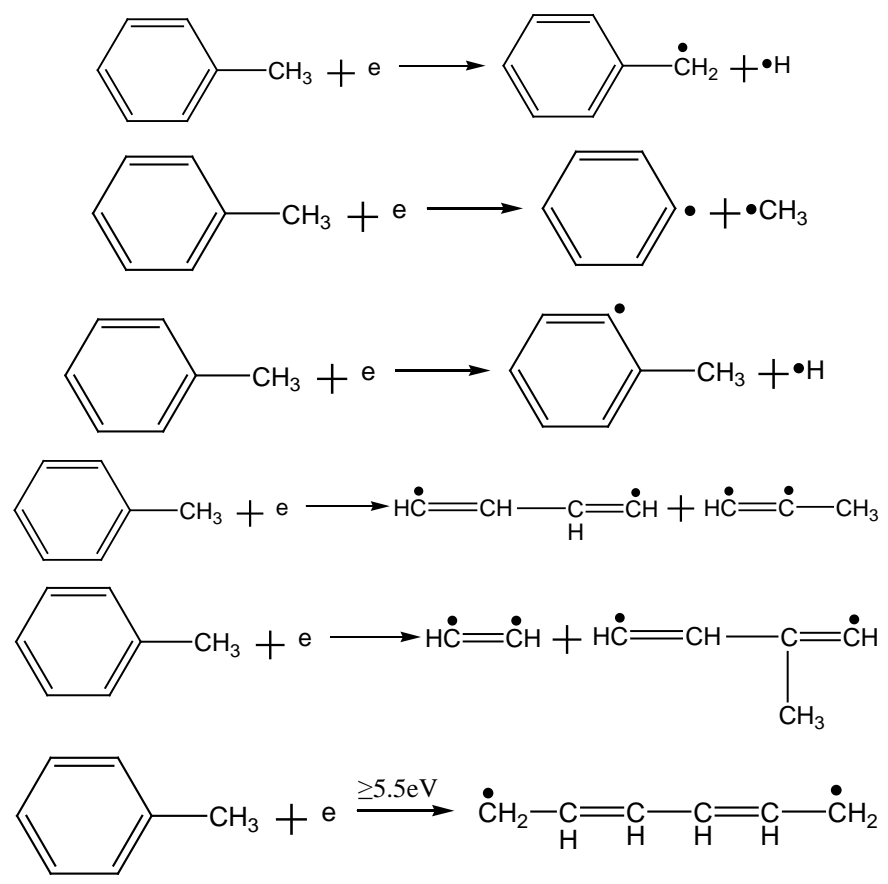

Equations (2)-(7) indicate the possible reactions of the decomposition process of toluene molecules, bond energy between carbon of benzene ring and carbon of substituent radical is $3.6 \mathrm{eV}$, which is the lower than that of carbon-carbon bond or hydrocarbon bond. In the structure of toluene molecules, the hydrogen of benzene ring is replaced by a methyl group, leading to a less stable bonding. In the theoretical point of view, this bond is the most vulnerable. Of course, the other bonds are also likely to be destroyed if the energy of the electrons is high enough.

According to the other reaction mechanisms, high energy electrons react with air to form $\mathrm{OH}^{\bullet}, \mathrm{O}^{\bullet}, \mathrm{H}^{\bullet}, \mathrm{HO}_{2}{ }^{\bullet}$, $\mathrm{N}^{\bullet}$ and $\mathrm{O}_{3}$ etc. in the first step of the reactions.

Then, these radical groups react with the toluene molecules or the other reaction groups, and the products are $\mathrm{CO}_{2}$, $\mathrm{CO}$ and $\mathrm{H}_{2} \mathrm{O}$ with increasing electric field strength or RED at last:

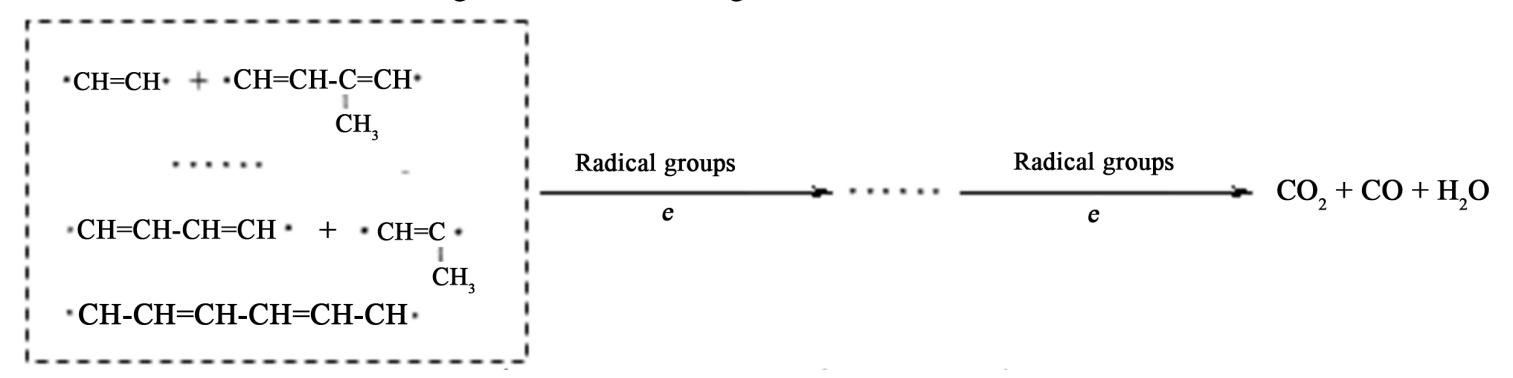

\section{Results and Discussions}

\subsection{Detection of Packed Materials}

The crystal structure of $\mathrm{Ba}_{0.8} \mathrm{Sr}_{0.2} \mathrm{Zr}_{0.1} \mathrm{Ti}_{0.9} \mathrm{O}_{3}$ is detected by XRD as shown in Figure 3. The crystal structure should be similar to cube crystal structure of calcium-titanium oxide. $\mathrm{Ba}_{0.8} \mathrm{Sr}_{0.2} \mathrm{Zr}_{0.1} \mathrm{Ti}_{0.9} \mathrm{O}_{3}$ was a type of ferroelectric like $\mathrm{BaTiO}_{3}$. The average diameter of sample particulates is of $59 \mathrm{~nm}$. The BET surface area of the $\mathrm{Ba}_{0.8} \mathrm{Sr}_{0.2} \mathrm{Zr}_{0.1} \mathrm{Ti}_{0.9} \mathrm{O}_{3}$ powders are $8.8 \mathrm{~m}^{2} / \mathrm{g}$, and Longmuir surface area detected by Micrometrics are $12.3 \mathrm{~m} / \mathrm{g}$ respectively. The relative permittivity of $\mathrm{Ba}_{0.8} \mathrm{Sr}_{0.2} \mathrm{Zr}_{0.1} \mathrm{Ti}_{0.9} \mathrm{O}_{3}$ detected by LCR is about 12000 . 


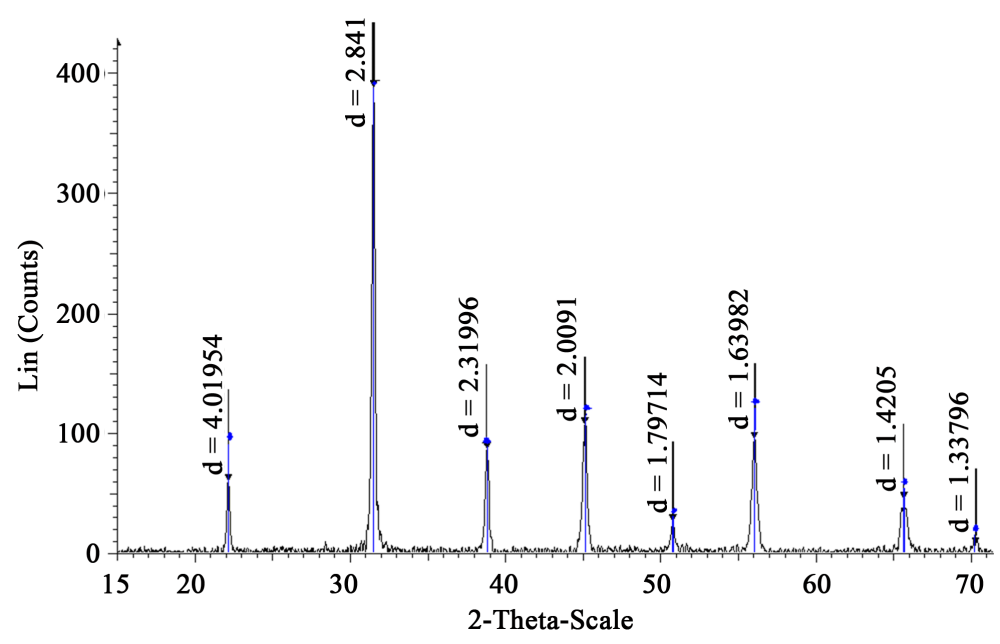

Figure 3. XRD testing results of $\mathrm{Ba}_{0.8} \mathrm{Sr}_{0.2} \mathrm{Zr}_{0.1} \mathrm{Ti}_{0.9} \mathrm{O}_{3}$.

\subsection{Effect of Electric Field Strength on Decomposition Efficiency of Toluene}

Figure 4 and Figure 5 show the relationship between decomposition efficiency of toluene and electric field strength in the plasma reactor. With increasing electric field strength, the decomposition efficiency of toluene increases.

The relationship between gas flow velocity and decomposition efficiency of toluene in the plasma reactor is shown decomposition efficiency increases with gas flow velocity decreasing when gas passes the reactor, and electric field strength is fixed as shown in Figure 4. The reason is gas flow velocity is lower and the reaction time is longer in the plasma reactor.

Figure 5 shows decomposition efficiency reduces with initial concentration of toluene increasing. When initial concentration of toluene is $600 \mathrm{mg} / \mathrm{m}^{3}$, the average electric field strength is $14.2 \mathrm{kV} / \mathrm{cm}$, the decomposition efficiency of toluene arrives at $95 \%$ in the reactor with packed materials coated nano-materials.

In the reactor, the space occupied by contamination air is always full of high energy electrons [12]. When effective collisions between high energy electrons and toluene molecules take place in the reactor, electron energy will destruct molecular structure of toluene and toluene molecules transform into $\mathrm{CO}_{2}, \mathrm{CO}$ and $\mathrm{H}_{2} \mathrm{O}$. Thus, decomposition efficiency of toluene is proportional to the electrons. When packed materials coated with nano-materials placed into the plasma reactor, with electric field strength increasing, more and more high energy electrons are produced due to mediums polarization of packed materials. So the packed materials in the reactor increase the decomposition efficiency of toluene.

\subsection{Effect of Nano-Materials on Decomposition Efficiency of Toluene}

Figure 6 shows the trend of decomposition efficiency of four kinds of reactors, i.e. (1) empty reactor; (2) original packed materials in plasma reactor; (3) packed materials coated $\mathrm{BaTiO}_{3}$ in plasma reactor; (4) packed materials coated nano-materials in plasma reactor. In the same electric field strength, the performance of decomposition efficiency of toluene represents $\eta(4)>\eta(3)>\eta(2)>\eta(1)$. The decomposition efficiency of packed materials in reactor is higher than that of no filler in reactor. Because packed materials in plasma reactor enhances the intensity of corona discharge and heightens decomposition effect of toluene.

It must be noted that decomposition efficiency of toluene $\eta(3)$ and $\eta(2)$ is less than $\eta(1)$ while electric field strength is low $(<7 \mathrm{kv} / \mathrm{cm})$, whereas $\eta(3)>\eta(2)>\eta(1)$ in high electric field strength $(>8 \mathrm{kV} / \mathrm{cm})$. The reason is the region of corona discharge is limited to the near corona line in lower electric field strength. There are no packed materials in plasma reactor, where there is no barrier to free electrons and active radicals moving. Whereas packed materials in plasma reactor are polarized only in the near corona line. At the same time, the free electrons and active radicals are hampered by filler. So no filler in plasma reactor has higher decomposition efficiency than the other reactors in lower electric field strength. However, the region of corona discharge expands to a larger scope in high electric field strength. The polarization part of packed materials also expands to the larger scope, and even expands to the entire reaction tube. The number of free electrons and active radicals are 


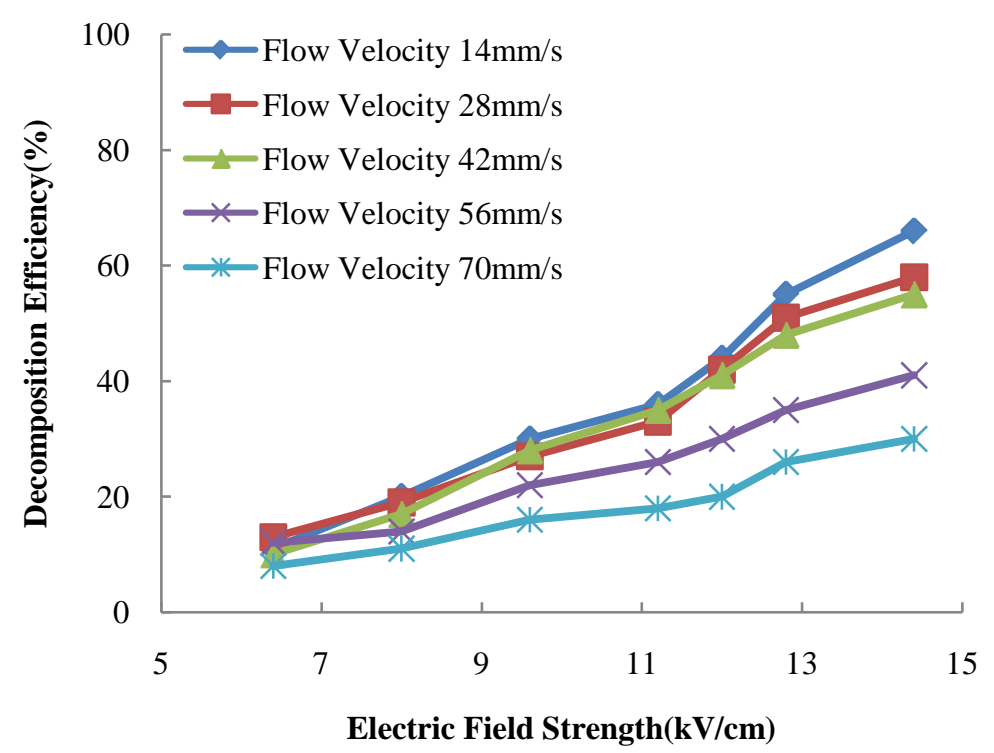

Figure 4. Relationship between electric field strength and decomposition efficiency under different flow velocities.

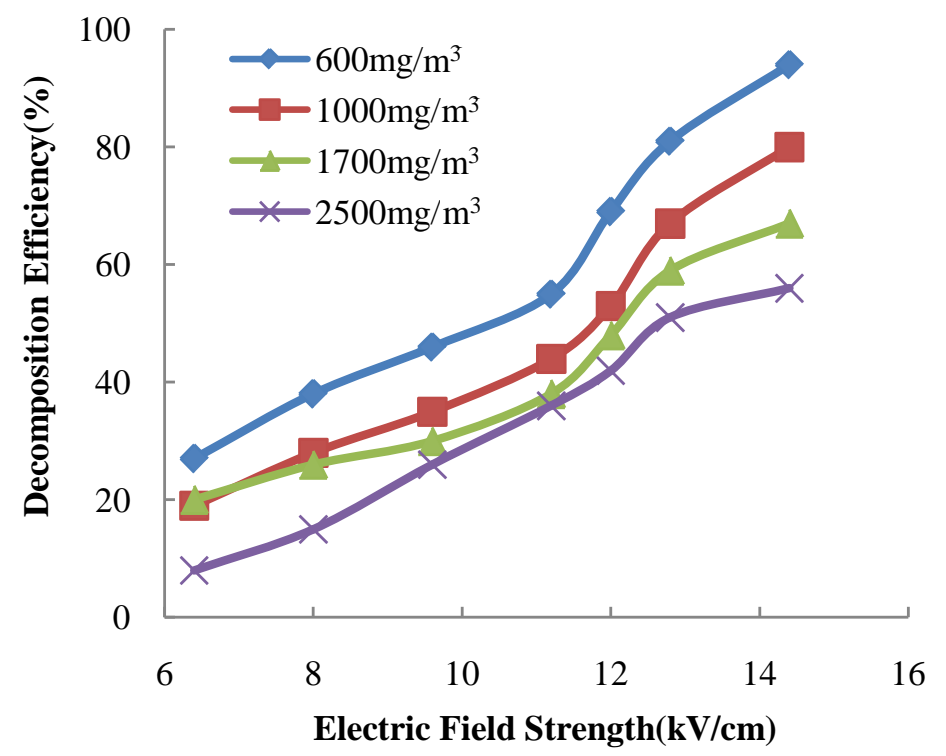

Figure 5. Relationship between electric field strength and decomposition efficiency under different concentrations.

more than no filler in plasma reactor, which result a higher decomposition efficiency in higher electric field strength. Especially, $\mathrm{BaTiO}_{3}$ as a kind of packed materials holding a type ferroelectric structure, improve corona discharge strength so that filler enhance electric field strength largely.

In Figure 6, it is clearly that (4) always display a better decomposition efficiency of toluene. Packed materials coated nanometer $\mathrm{Ba}_{0.8} \mathrm{Sr}_{0.2} \mathrm{Zr}_{0.1} \mathrm{Ti}_{0.9} \mathrm{O}_{3}$ in plasma reactor not only have the ferroelectric characteristic to improve discharge forms and strengthened electric field strength [13] [14], but hold the characteristic of nano-materials. The soft chemical approach was used to prepare nano-materials. A fitting quantity of strontium, zinc and zirconium were adulterated in $\mathrm{BaTiO}_{3}$ [15]. These metal ions equably entered into crystal lattice of $\mathrm{BaTiO}_{3}$ and caused Curie temperature(Tc) fallen. As a result, dielectric constant is 12 times higher than $\mathrm{BaTiO}_{3}$ pure phase, and dielectric losses are reduced to $1 / 6$ in room temperature. As a kind of nano-materials and a kind of solid catalyst, its activity is determined by its chemical and phase composition, crystal structure and activity surface area. 




Figure 6. Relationship between packed materials and decomposition efficiency.

Because of its surface ultrafine particles (mean particle size of 40 - $90 \mathrm{~nm}$ and the specific surface area of 8.7943 $\mathrm{m}^{2} / \mathrm{g}$ ), nano-materials increase the specific surface area of catalyst greatly. The fitting quantity of strontium, zinc and zirconium are adulterated to destroy the crystal structure of $\mathrm{BaTiO}_{3}$ and to make them exist more hole in order to heighten catalytic activity. Therefore, packed materials in room temperature and small electric field strength can be polarized to strengthen plasma role in enhancing the energy efficiency of reactor and generating more efficient oxides to increase decomposition efficiency of toluene.

\subsection{Relationship between Energy Distribution and Decomposition Efficiency of Toluene}

From Table 1, we can find that energy consumption (P) of toluene decomposition states $\mathrm{P}(1)>\mathrm{P}(2)>\mathrm{P}(3)>$ $\mathrm{P}(4)$ to achieve the same decomposition efficiency. This results show that packed materials coated nano-meterials in plasma reactor can play a role in reducing energy consumption to deal with the same quantity of toluene.

In Figure 7, pillars represent different reactors hold the status of energy distribution (R). It is clearly that decomposition efficiency of toluene is higher and energy efficiency is higher in packed materials coated nano-materials in plasma reactor. At the same decomposition efficiency, the distribution of energy consumption shows that $\mathrm{R}(4)<\mathrm{R}(3)<\mathrm{R}(2)<\mathrm{R}(1)$. This result illuminates that the plasma reactor packed materials coated nano-materials are effectively realized to toluene decomposition.

The reason is that $\mathrm{Ba}_{0.8} \mathrm{Sr}_{0.2} \mathrm{Zr}_{0.1} \mathrm{Ti}_{0.9} \mathrm{O}_{3}$ has the ferroelectric characteristic to improve discharge forms and strengthened electric field strength, and dielectric constant arrives at above $10^{4}$ at room temperature. At the same time, $\mathrm{Ba}_{0.8} \mathrm{Sr}_{0.2} \mathrm{Zr}_{0.1} \mathrm{Ti}_{0.9} \mathrm{O}_{3}$ holds the characteristic of nano-materials. So the results confirm above theory and show a good application prospects.

\section{Conclusions}

Effects of electric field strength (voltage strength), toluene concentration of influent, influent flow rate, reactor packing and material of the fillers on toluene decomposition rate were determined. The decomposition efficiency of toluene increased with increasing electric field strength and/or influent flow rate while decreased with the rising influent toluene concentration. Packing the reactor with inert fillers improved the toluene decomposition rate and that packing with nano $\mathrm{BaTiO}_{3}$ catalyst coated fillers resulted in greater enhancement. More ozone was produced in the reactor packed with catalyst coated fillers and at rising voltage strength up to $13 \mathrm{kV} / \mathrm{cm}$. The 


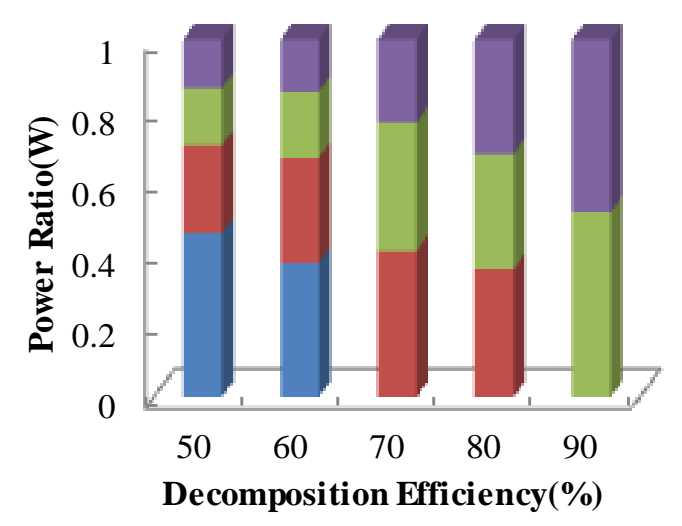

$$
\begin{aligned}
& \text { packed materials coated nano-materials } \\
& \text { packed materials coated } \mathrm{BaTiO}_{3} \\
& \text { original packed materials } \\
& \text { empty }
\end{aligned}
$$

\begin{tabular}{|c|c|c|c|c|c|}
\hline Decomposition Efficiency (\%) & 50 & 60 & 70 & 80 & 90 \\
\hline (1) Empty & 25 & 28 & - & - & - \\
\hline (2) Original packed materials & 13.4 & 22 & 25 & 28 & - \\
\hline (3) Packed materials coated $\mathrm{BaTiO}_{3}$ & 8.7 & 13.75 & 22 & 25.2 & 28 \\
\hline (4) Packed materials coated nano-materials & 7.5 & 10.9 & 14.3 & 25 & 26.1 \\
\hline
\end{tabular}

Figure 7. Relationship between power ratio and decomposition efficiency of toluene.

Table 1. Relationship between power and decomposition efficiency under different packed materials.

mechanism of toluene decomposition due to plasma and catalyst actions was proposed. Operating over 13 $\mathrm{kV} / \mathrm{cm}$, decomposition efficiency of toluene in the influent (flow rate $=0.3 \mathrm{~m} / \mathrm{h}$, containing $600 \mathrm{mg} / \mathrm{L}$ of toluene) was up to $95 \%$ in the reactor filled with catalyst coated fillers.

Series of experiments were performed in a small reactor (44 mm ID $\times 200 \mathrm{~mm}$ working volume) to remove toluene from a gaseous influent at the room temperature and atmospheric pressure by decomposition due to DBD (dielectric barrier discharge) generated non-thermal plasma.

1) The decomposition efficiency of toluene increased with the increasing electric field strength.

2) Packing the reactor with inert fillers improved the decomposition efficiency of toluene and that packing with nano-catalyst coated fillers resulted in greater enhancement. Operating at $14.2 \mathrm{kV} / \mathrm{cm}$, decomposition efficiency of toluene in the influent (flow rate $=0.3 \mathrm{~m}^{3} / \mathrm{h}$, containing $600 \mathrm{mg} / \mathrm{L}$ of toluene) was up to $95 \%$ in the reactor filled with catalyst coated fillers.

3) Energy consumption (P) of toluene decomposition in the plasma reactor packed materials coated nano-materials states $\mathrm{P}(1)>\mathrm{P}(2)>\mathrm{P}(3)>\mathrm{P}(4)$ to achieve the same decomposition efficiency. At the same decomposition efficiency, the distribution of energy consumption shows that $\mathrm{R}(4)<\mathrm{R}(3)<\mathrm{R}(2)<\mathrm{R}(1)$. So nano-materials is effectively realized to toluene decomposition and plays a role in reducing energy consumption to deal with the same quantity of toluene.

\section{Acknowledgements}

This work was supported by Program for New Century Excellent Talents in University (No.NCET120967), and Beijing Outstanding Talent Training Project (No.2012ZG81), and the National Natural Science Foundation of China (No.51108453), and the Fundamental Research Funds for the Central Universities (No.2009QH03). 


\section{References}

[1] de Nevers, N. (2000) Air Pollution Control Engineering. 2nd Edition, McGraw-Hill, Beijing.

[2] Guangda, M. (2003) Air Pollution Control Engineering. 2nd Edition, China Environmental Science Publishing Company, Beijing.

[3] Guowen, L., Fan, Q.J. and Liu, Q. (1998) The Control Technique over the Pollution Caused by VOCs. Journal of Xi'an University of Architecture \& Technology, 30, 399-402.

[4] Futamura, S., Einaga, H. and Kabashima, H., et al. (2004) Synergistic Effect of Silent Discharge Plasma and Catalysts on Benzene Decomposition. Catalysis Today, 89, 89-95. http://dx.doi.org/10.1016/j.cattod.2003.11.014

[5] Urashima, K. and Chang, J. (2000) Removal of Volatile Organic Compounds from Air Streams and Industrial Flue Gases by Non-Thermal Plasma Technology. IEEE Transaction on Dielectrics and Electrical Insulation, 7, 602-614. http://dx.doi.org/10.1109/94.879356

[6] Ogata, A., Yamanonchi, K., Mizuno, K., et al. (1999) Decomposition of Benzene Using Alumina-Hybrid and Catalyst-Hybrid Plasma Reactors. IEEE Transaction on Industry Application, 35, 1289-1295. http://dx.doi.org/10.1109/28.806041

[7] Einaga, H., Lbusuki, T. and Futamura, S. (2001) Performance Evaluation of a Hybrid System Comprising Silent Discharge Plasma and Manganese Oxide Catalysts for Benzene Decomposition. IEEE Transaction on Industry Application, 37, 858-863. http://dx.doi.org/10.1109/28.952524

[8] Guo, Y.-F., Ye, D.-Q., Chen, K.-F., et al. (2006) Toluene Decomposition Using a Wire-Plate Dielectric Barrier Discharge Reactor with Manganese Oxide Catalyst in Situ. Journal of Molecular Catalysis A: Chemical, 245, 93-100. http://dx.doi.org/10.1016/j.molcata.2005.09.013

[9] Li, R.X., et al. (2006) Plasma Catalysis for CO2 Decomposition by Using Different Dielectric Materials. Fuel Processing Technology, 87, 617-622. http://dx.doi.org/10.1016/j.fuproc.2006.01.007

[10] Malik, M.A. and Jiang, X.Z. (2000) Catalyst Assisted Destruction of Trichloro Ethylene and Toluene in Corona Discharges. Journal of Environmental Sciences, 12, 7-11.

[11] Subrahmanyam, Ch., Renken, A. and Kiwi-Minsker, L. (2007) Novel Catalytic Non-Thermal Plasma Reactor for the Abatement of VOCs. Chemical Engineering Journal, 134, 78-83. http://dx.doi.org/10.1016/j.cej.2007.03.063

[12] Yang. J.J. (1983) Gas Discharge. Science Publishing Company, Beijing.

[13] Jian, L. and Guang-da, M. (2000) The Mechanismic Analysis and Experiment on Controlling Volatile Organic Compounds (VOCs) with Corona Discharge. Journal of Xi' an University of Architecture \& Technology, 32, 24-27.

[14] West, A.R. (1984) Solid State Chemistry and Its Applications. John Wiley Sons Ltd., New Delhi, 534-540.


in China Series B, 31, 525-529. 